\title{
Impact of tyrosine kinase inhibitors and cytoreductive nephrectomy in patients with metastatic renal cell carcinoma
}

\author{
Wassim Kassouf, MD, FRCSC
}

See related article on page 281

U ntil recently, the standard of care for metastatic renal cell carcinoma (mRCC) has been cytoreductive nephrectomy $(\mathrm{CN})$ followed by systemic immunotherapy in the form of interferon- $\alpha$ (IFN- $\alpha$ ). As of 2007, there was a paradigm shift; a prospective randomized trial comparing sunitinib versus IFN- $\alpha$ in patients with $\mathrm{mRCC}$ showed superior progression-free survival in the sunitinib arm, ${ }^{1}$ and more recently, an update on this trial was published showing prolonged overall survival in patients treated with sunitinib compared with IFN- $\alpha$ (median survival 26.4 v. 21.8 mo). ${ }^{2}$ Patients in the IFN- $\alpha$ arm had longer overall survival than was previously published, in part owing to the crossover in patients who used a tyrosine kinase inhibitor (TKI) after treatment with IFN- $\alpha$ failed. In general, patients enrolled in phaseIII trials are selected for good performance status and lack of clinically important comorbidities and, as such, may not always represent the general patient population. Warren and colleagues $^{3}$ aimed to evaluate the effect of TKIs (compared with IFN- $\alpha$ ) on survival in patients with mRCC in the "real world" clinical practice setting. The authors confirmed the benefits of TKIs compared with IFN- $\alpha$ in these patients. Overall survival rates for patients treated with IFN- $\alpha$ were inferior compared with those treated with TKIs as first-line and second-line therapy (10.0 v. 15.8 and 19.5 mo, respectively).

Presently, it is widely accepted that $\mathrm{CN}$ remains an integral aspect in the management of patients with mRCC. This practice was based on 2 prospective randomized trials that evaluated $\mathrm{CN}$ in patients with $\mathrm{mRCC}$ who were treated with immunotherapy and demonstrated a significant survival benefit in patients who underwent $\mathrm{CN} .{ }^{4,5}$ However, both trials were not able to provide mechanistic insight for the survival benefit conferred by CN. Several biological hypotheses have been proposed, supporting the theory that immunosuppressive activity is reversed after $\mathrm{CN}$ owing to resection of the primary tumour. Whether or not the benefit of $\mathrm{CN}$ persists in the TKI era is unclear as there is no level- 1 evidence evaluating the role of $\mathrm{CN}$ in patients treated with TKIs. In contrast, it would be unrealistic to expect a repeat phase-III trial to revalidate the benefits of $\mathrm{CN}$ for each novel class of agents that show efficacy in the treatment of mRCC. As such, many urological and medical oncologists have embraced $\mathrm{CN}$ even in the TKI era by extrapolating the data from the studies that used immunotherapy as systemic therapy. Interestingly, Warren and colleagues showed that prior nephrectomy was independently associated with improved survival in patients treated with TKIs. Although I support the role of $\mathrm{CN}$ in patients with mRCC treated with TKIs, one has to be careful when assessing the therapeutic impact of $\mathrm{CN}$ in a retrospective series because of confounding variables with having or not having $\mathrm{CN}$ before systemic therapy. Lastly, one should also note that the previous evidence supporting the use of $\mathrm{CN}$ was largely based on patients with mRCC of clear cell histology. When we examined the M.D. Anderson experience treating patients with mRCC $(n=606)$, the outcome of patients treated with CN and systemic therapy for mRCC with nonclear cell histology was dismal compared with patients with clear cell histology (median survival 9.7 v. 20.3 mo). ${ }^{6}$ This raises yet another concern of whether or not patients who have mRCC with nonclear cell histology should be treated with systemic therapy alone without an upfront $\mathrm{CN}$.

Assistant Professor, McGill University Health Centre

Competing interests: None declared.

\section{References}

1. Motzer RJ, Hutson TE, Tomczak P, et al. Sunitinib versus interferon alfa in metastatic renal-cell carcinoma. N Engl J Med 2007;356:115-24.

2. Motzer RJ, Hutson TE, Tomczak $P$, et al. Overall survival and updated results for sunitinib compared with interferon alfa in patients with metastatic renal cell carcinoma. J Clin Oncol 2009 June 1. [Epub ahead of print].

3. Warren $M$, Venner PM, North S, et al. A population-based study examining the effect of tyrosine kinase inhibitors on survival in metastatic renal cell carcinoma in Alberta and the role of nephrectomy prior to treatment. Can Urol Assoc J 2009;3:281-9.

4. Mickisch GH, Garin A, van Poppel H, et al. Radical nephrectomy plus interferon-alfa-based immunotherapy compared with interferon alfa alone in metastatic renal-cell carcinoma: a randomised trial. Lancet 2001;358:966-70.

5. Flanigan RC, Salmon SE, Blumenstein BA, et al. Nephrectomy followed by interferon alfa-2b compared with interferon alfa-2b alone for metastatic renal-cell cancer. N Engl J Med 2001;345:1655-9.

6. Kassouf W, Sanchez-0ritz R, Tamboli P, et al. Cytoreductive nephrectomy for metastatic renal cell carcinoma with nonclear cell histology. J Urol 2007;178:1896-900.

Correspondence: Dr. W. Kassouf; wassim.kassouf@muhc.mcgill.ca 